\title{
COMBINAÇÕES DE FONTES DE NITROGÊNIO NO DESENVOLVIMENTO E RENDIMENTO DO FEIJOEIRO ${ }^{1}$
}

\author{
Renato José Afonso 2 , Orivaldo Arf ${ }^{3}$, Denis Santiago da Costa 4 , \\ Rafael Marani Barbosa ${ }^{5}$, Salatier Buzetti ${ }^{3}$, Marco Eustáquio de Sá ${ }^{3}$, Ricardo Antônio Ferreira Rodrigues ${ }^{3}$
}

\begin{abstract}
COMBINATION OF NITROGEN SOURCES

ON COMMON BEAN GROWTH AND YIELD

Nitrogen is one of the most lixiviated plant nutrients on soil and it can also be dispersed in its gaseous form, limiting many crops yield. Thus, this study aimed to evaluate the effect of $\mathrm{N}$ sources (urea and ammonium sulfate) combinations, at $80 \mathrm{~kg} \mathrm{ha}^{-1}$, isolated or combined, with or without irrigation water incorporated to the soil. The experiment was carried out in Selvíria, Mato Grosso do Sul State, Brazil, during two growing seasons (2003 and 2004), in the winter, by using a randomized block design with 12 treatments, in a $6 \times 2$ factorial scheme, with four replications. Six N sources combinations were used: control (without $\mathrm{N}$ ); $80 \mathrm{~kg} \mathrm{ha}^{-1}$ of $\mathrm{N}$ - ammonium sulfate (AS); $20 \mathrm{~kg} \mathrm{ha}^{-1}$ of $\mathrm{N}$ - urea (U) $+60 \mathrm{~kg} \mathrm{ha}^{-1}$ of $\mathrm{N}(\mathrm{AS}) ; 40 \mathrm{~kg} \mathrm{ha}^{-1}$ of $\mathrm{N}(\mathrm{U})+$ $40 \mathrm{~kg} \mathrm{ha}^{-1}$ of N (AS); $60 \mathrm{~kg} \mathrm{ha}^{-1}$ of N (U) $+20 \mathrm{~kg} \mathrm{ha}^{-1}$ of N (AS); and $80 \mathrm{~kg} \mathrm{ha}^{-1}$ of $\mathrm{N}(\mathrm{U})$, with and without addition of irrigation water. It was possible to conclude that the nitrogen supply, regardless of the source used, provided an increase in grain yield. No difference was observed, concerning the nitrogenous fertilizer incorporated or not to the soil with irrigation water.
\end{abstract}

KEY-WORDS: Phaseolus vulgaris L.; urea; ammonium sulfate; no-tillage.

\section{INTRODUÇÃO}

O feijoeiro comum é uma das mais importantes culturas do Brasil, uma vez que o feijão é considerado a principal fonte de proteínas da população de menor poder aquisitivo, e apresenta, ainda, como vantagem, a possibilidade de cultivo em diferentes épocas do ano, em períodos definidos como "das águas", "da seca" e "de inverno".

\section{RESUMO}

O nitrogênio é um dos nutrientes de planta mais lixiviados no solo, sendo, também, perdido na forma gasosa, o que pode limitar o rendimento de muitas culturas. Neste sentido, este trabalho objetivou estudar o efeito de combinações de fontes de $\mathrm{N}$ (ureia e sulfato de amônio), na dose de $80 \mathrm{~kg} \mathrm{ha}^{-1}$, em aplicação isolada ou em mistura, com ou sem incorporação ao solo de água de irrigação, sobre a produção e os componentes de rendimento da cultura do feijoeiro. O trabalho foi realizado no município de Selvíria (MS), em dois anos agrícolas (2003 e 2004), no período de inverno. Adotou-se o delineamento em blocos ao acaso, com 12 tratamentos dispostos em esquema fatorial $6 \times 2$, com quatro repetições. Os tratamentos foram constituídos por seis combinações de fontes de nitrogênio: testemunha - sem N; $80 \mathrm{~kg} \mathrm{ha}^{-1}$ de $\mathrm{N}$ - sulfato de amônio (SA); $20 \mathrm{~kg} \mathrm{ha}^{-1}$ de N - ureia (U) $+60 \mathrm{~kg} \mathrm{ha}^{-1} \mathrm{de} \mathrm{N}(\mathrm{SA}) ; 40 \mathrm{~kg} \mathrm{ha}^{-1}$ de $\mathrm{N}(\mathrm{U})+40 \mathrm{~kg} \mathrm{ha}^{-1}$ de N (SA); $60 \mathrm{~kg} \mathrm{ha}^{-1} \mathrm{de} \mathrm{N}(\mathrm{U})+20 \mathrm{~kg} \mathrm{ha}^{-1}$ de $\mathrm{N}$ (SA); e $80 \mathrm{~kg} \mathrm{ha}^{-1}$ de $\mathrm{N}(\mathrm{U})$, aplicadas com e sem água de irrigação. Verificou-se que o fornecimento de nitrogênio, independentemente da fonte utilizada, propiciou aumento na produtividade de grãos. Não houve diferença entre a incorporação ou não do fertilizante nitrogenado ao solo com água de irrigação.

PALAVRAS-CHAVE: Phaseolus vulgaris L.; ureia; sulfato de amônio; plantio direto.

A absorção de nitrogênio é realizada durante todo o ciclo da cultura, porém, a época de maior exigência ocorre entre os 35 e 50 dias da emergência das plantas, coincidindo com o período de florescimento, no qual a planta absorve de $2,0 \mathrm{~kg} \mathrm{ha}^{-1}$ a $2,5 \mathrm{~kg} \mathrm{ha}^{-1}$ ao dia, sendo que a deficiência deste nutriente causa vários distúrbios fisiológicos na planta (Arf et al. 1999). Assim, a baixa disponibilidade de nitrogênio tem sido considerada um dos principais fatores li-

1. Trabalho recebido em nov./2010 e aceito para publicação em set./2011 (n registro: PAT 12360/ DOI: 10.5216/pat.v41i3.12360).

2. Banco Bradesco S. A., São Paulo, SP, Brasil.E-mail: renatojoseafonso@hotmail.com.

3. Universidade Estadual Paulista, Faculdade de Engenharia (FE/Unesp), Ilha Solteira, SP, Brasil.

E-mails: arf@agr.feis.unesp.br, mesa@agr.feis.unesp.br, sbuzetti@agr.feis.unesp.br, ricardo@agr.feis.unesp.br.

4. Universidade de São Paulo, Escola Superior de Agricultura "Luiz de Queiroz" (ESALQ/USP), Departamento de Produção

Vegetal, Piracicaba, SP, Brasil. E-mail: the_denis@hotmail.com.

5. Universidade Estadual Paulista, Faculdade de Ciências Agrárias e Veterinárias (FCAV/Unesp), Departamento de Produção Vegetal, Jaboticabal, SP, Brasil.E-mail: rmarani@gmail.com. 
mitantes à obtenção de rendimentos elevados nesta cultura.

De acordo com Barbosa Filho \& Silva (2001), o sulfato de amônio e a ureia são as duas fontes de $\mathrm{N}$ mais utilizadas na agricultura brasileira, possivelmente por apresentarem menor custo e maior disponibilidade no mercado. Enquanto outras fontes de $\mathrm{N}$ não estiverem disponíveis no mercado, em condições competitivas com a ureia e o sulfato de amônio, a estratégia para maximizar a eficiência de uso de $\mathrm{N}$ ainda deverá ser o aperfeiçoamento de seu próprio manejo. Os mesmos autores afirmaram que a ureia, aplicada superficialmente e com uso da irrigação, foi a opção com maior retorno econômico, para adubação nitrogenada em cobertura.

De acordo com Lara Cabezas et al. (2000), a incorporação da ureia praticamente elimina as perdas por volatilização de amônia, porque aumenta o contato entre o fertilizante e o solo, favorecendo a adsorsão de $\mathrm{NH}_{4}^{+}$às cargas negativas. Silva et al. (2004) observaram que a incorporação da ureia diminuiu, em até $90 \%$, as perdas de $\mathrm{NH}_{3}$, em relação à aplicação superficial. Já Rosa et al. (2004) verificaram que as perdas de nitrogênio por volatilização são menores em solos úmidos.

Barbosa Filho et al. (2004) avaliaram a influência da calagem na adubação de cobertura do feijoeiro com ureia e sulfato de amônio e verificaram que a calagem não influenciou na eficiência da adubação de cobertura. Segundo os autores, a ureia e o sulfato de amônio não diferiram, quanto à eficiência, como fonte de nitrogênio às plantas, em termos de rendimento de grãos, em duas safras, apresentando a ureia a maior margem de lucro. Resultados semelhantes foram observados por Binotti et al. (2005), que avaliaram a eficiência de diferentes fontes de nitrogênio na cultura do feijoeiro.

Segundo Villas Boas et al. (2005), a mistura de ureia com fertilizantes de características ácidas, aplicada ao solo, pode aumentar a concentração de íons $\mathrm{H}^{+}$próximos do grânulo e promover a dimi- nuição das perdas de N por volatilização. Dentre os fertilizantes nitrogenados mais utilizados, o sulfato de amônio é a fonte com caráter mais ácido, além de não sofrer volatilização do nitrogênio amoniacal, quando o pH é inferior a 7 (Volk 1959). Vitti et al. (2002) constataram que a mistura de ureia com sulfato de amônio reduziu as perdas de amônia.

Assim, ressalta-se a importância da adubação nitrogenada, evidenciando a necessidade de se aplicar os conhecimentos sobre estas práticas ao cultivo do feijão, visando à obtenção de produtividades mais elevadas. Neste sentido, a mistura de ureia com sulfato de amônio pode ser uma alternativa interessante.

Assim, este trabalho objetivou estudar o efeito de combinações de fontes de $\mathrm{N}$ (ureia e sulfato de amônio), na dose de $80 \mathrm{~kg} \mathrm{ha}^{-1}$, em aplicação isolada ou em mistura, com ou sem incorporação ao solo com água de irrigação, sobre a produção e os componentes de rendimento da cultura do feijoeiro.

\section{MATERIAL E MÉTODOS}

O trabalho foi desenvolvido em área experimental pertencente à Faculdade de Engenharia da Unesp, Campus de Ilha Solteira, localizada no município de Selvíria (MS), no outono-inverno de 2003 e 2004, com uso de irrigação. O solo do local foi classificado como Latossolo Vermelho distrófico típico argiloso (Embrapa 2006). A precipitação média anual é de $1.370 \mathrm{~mm}$, a temperatura média anual de $23,5^{\circ} \mathrm{C}$ e a umidade relativa do ar de $70-80 \%$ (média anual). Os dados climáticos referentes à área de cultivo do feijoeiro, nos dois anos de experimentação, são apresentados nas Figuras 1 e 2.

Antes da instalação dos experimentos, amostras de solo foram coletadas na área experimental, para determinação dos atributos químicos, de acordo com metodologia proposta por Raij \& Quaggio (1983), cujos resultados são apresentados na Tabela 1.

Os tratamentos foram instalados em áreas cuja implantação do sistema de semeadura direta foi

Tabela 1. Análise química do solo, à profundidade de 0-0,20 m, amostrado antes da instalação do experimento, nos dois anos de condução (Selvíria, MS, 2003/2004)

\begin{tabular}{|c|c|c|c|c|c|c|c|c|c|c|c|}
\hline \multirow{2}{*}{ Ano } & $\mathrm{P}_{\text {resina }}$ & M.O. & $\mathrm{pH}$ & $\mathrm{K}$ & $\mathrm{Ca}$ & $\mathrm{Mg}$ & $\mathrm{H}+\mathrm{Al}$ & $\mathrm{Al}$ & CTC & SB & \multirow{2}{*}{$\frac{V}{(\%)}$} \\
\hline & $\mathrm{mg} \mathrm{dm} \mathrm{m}^{-3}$ & $\mathrm{~g} \mathrm{dm}^{-3}$ & $\mathrm{CaCl}_{2}$ & \multicolumn{7}{|c|}{$\mathrm{cmol}_{\mathrm{c}} \mathrm{dm}^{-3}$} & \\
\hline 2003 & 9 & 17 & 4,7 & 0,13 & 1,5 & 0,9 & 3,4 & 0,1 & 5,93 & 2,53 & 43 \\
\hline 2004 & 4 & 18 & 4,6 & 0,27 & 1,7 & 1,2 & 3,4 & 0,2 & 6,57 & 3,17 & 49 \\
\hline
\end{tabular}




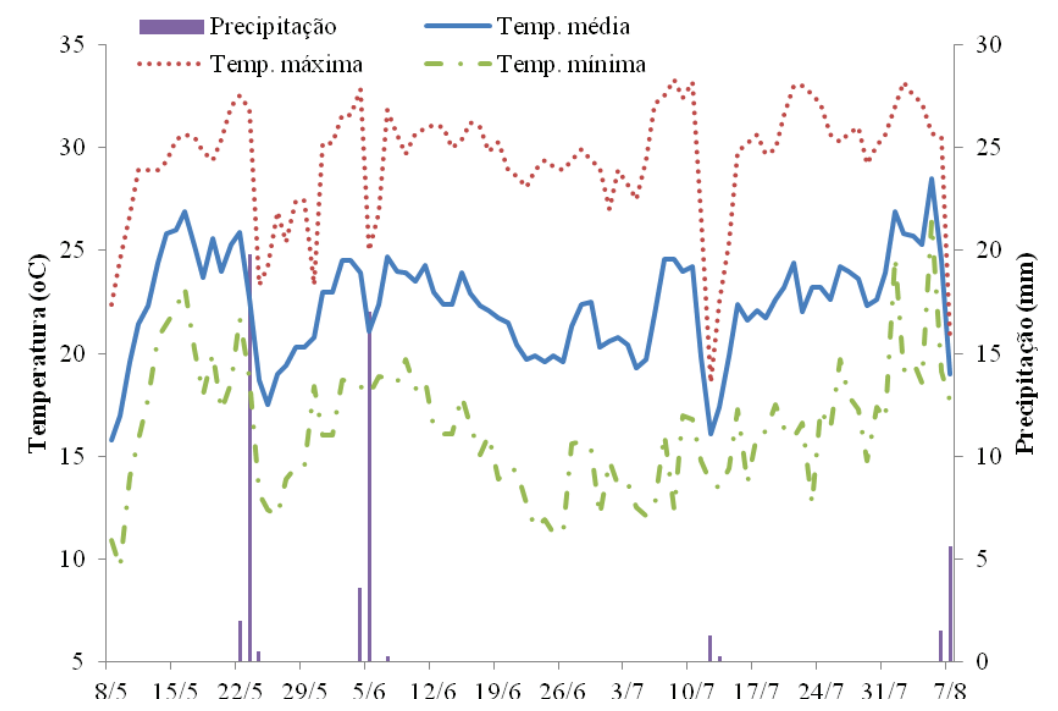

Figura 1. Dados climáticos do período de cultivo do feijoeiro (Selvíria, MS, 2003).

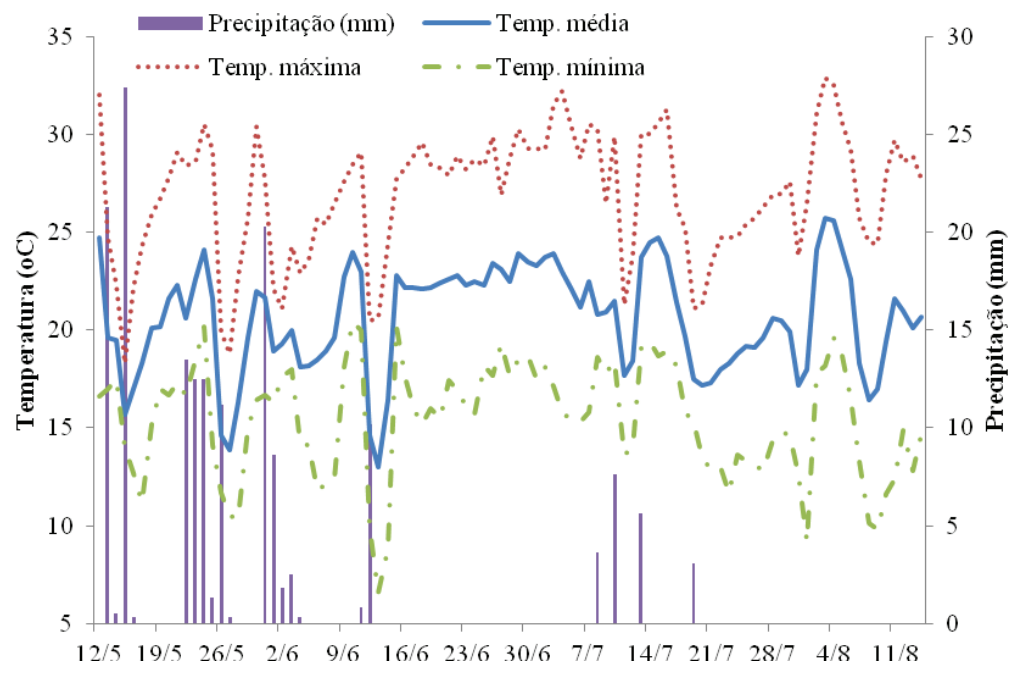

Figura 2. Dados climáticos do período de cultivo do feijoeiro (Selvíria, MS, 2004).

realizada no ano agrícola de 1996/1997, sendo que, anteriormente ao desenvolvimento da pesquisa, a área estava ocupada com culturas de arroz, no primeiro ano, e milho, no segundo.

O delineamento experimental utilizado foi o em blocos ao acaso, com 12 tratamentos dispostos em esquema fatorial $6 \times 2$, com quatro repetições. Os tratamentos constituíram-se de seis combinações de fontes de nitrogênio: testemunha - sem N; $80 \mathrm{~kg} \mathrm{ha}^{-1}$ de $\mathrm{N}$ - sulfato de amônio (SA); $20 \mathrm{~kg} \mathrm{ha}^{-1}$ de $\mathrm{N}$ - ureia (U) $+60 \mathrm{~kg} \mathrm{ha}^{-1}$ de N (SA); $40 \mathrm{~kg} \mathrm{ha}^{-1}$ de $\mathrm{N}(\mathrm{U})+40 \mathrm{~kg} \mathrm{ha}^{-1} \mathrm{de} \mathrm{N}(\mathrm{SA}) ; 60 \mathrm{~kg} \mathrm{ha}^{-1} \mathrm{de} \mathrm{N}(\mathrm{U})+$ $20 \mathrm{~kg} \mathrm{ha}^{-1}$ de N (SA); e $80 \mathrm{~kg} \mathrm{ha}^{-1}$ de N (U), aplicadas com e sem incorporação do fertilizante pela água de irrigação. As parcelas foram constituídas por 5 linhas de 6,0 $\mathrm{m}$ de comprimento, espaçadas em 0,50 m entre si, sendo a área útil constituída pelas 3 linhas centrais, desprezando-se $0,50 \mathrm{~m}$, em ambas as extremidades de cada linha.

$\mathrm{O}$ fornecimento de água foi realizado por um sistema fixo de irrigação por aspersão, no primeiro ano, e por um sistema do tipo pivô central, no segundo ano, sendo a quantidade de água calculada de acordo com a evapotranspiração da cultura. A área foi dessecada utilizando-se o herbicida glyphosate (1.560 $\mathrm{g} \mathrm{ha}^{-1}$ do i.a.). A semeadura foi realizada mecanicamente, nos dias 08/05/2003 e 12/05/2004, utilizando-se a cultivar IAC Carioca Eté, no primeiro ano, 
e a cultivar Pérola, no segundo ano de cultivo, com densidade de semeadura de 12 sementes viáveis $\mathrm{m}^{-1}$. As sementes receberam tratamento com carboxin + thiram $\left(200 \mathrm{~g}+200 \mathrm{~g}\right.$ do i.a. $100 \mathrm{~kg}$ de sementes $\left.{ }^{-1}\right)$.

A adubação de semeadura foi calculada de acordo com o resultado da análise química do solo e recomendações de Ambrosano et al. (1996), sendo constituída de $15 \mathrm{~kg} \mathrm{ha}^{-1}$ de $\mathrm{N}$ (ureia), $70 \mathrm{~kg} \mathrm{ha}^{-1}$ de $\mathrm{P}_{2} \mathrm{O}_{5}$ (superfosfato simples) e $30 \mathrm{~kg} \mathrm{ha}^{-1} \mathrm{de}_{2} \mathrm{O}$ $(\mathrm{KCl})$, nos dois anos de cultivo. Após a semeadura, a área foi irrigada, para promover a germinação das sementes. A emergência ocorreu aos sete dias após a semeadura, no primeiro ano, e aos seis dias após a semeadura, no segundo ano.

A adubação nitrogenada em cobertura, no primeiro e no segundo ano de cultivo, foi realizada, respectivamente, aos 15 e aos 18 dias após a emergência das plântulas (DAE), para os tratamentos com incorporação do nitrogênio aplicado, e aos 16 e 19 dias, para os tratamentos sem incorporação. Após a aplicação do nitrogênio em cobertura, nos tratamentos com incorporação pela água de irrigação, aplicou-se uma lâmina de $10 \mathrm{~mm}$. Tanto nos tratamentos com incorporação do nitrogênio via água de irrigação, quanto nos tratamentos sem incorporação, a adubação de cobertura foi realizada em horário com temperatura mais amena (final da tarde).

O controle de plantas daninhas foi realizado aos 23 e 21 dias, no primeiro e segundo ano de cultivo, respectivamente, utilizando-se o herbicida fluazifop-p-butil + fomesafen $\left(160 \mathrm{~g}+200 \mathrm{~g} \mathrm{ha}^{-1}\right.$ do i.a.). O controle e prevenção das principais pragas e doenças da cultura foram realizados com pulverizações com produtos recomendados para a cultura.

Foram realizadas as seguintes avaliações: massa seca das plantas no florescimento pleno (coletadas em $\mathrm{R}_{6}$, acondicionadas em sacos de papel e levadas para estufa de circulação forçada de ar, até atingirem massa constante); teor de nitrogênio foliar (coletada a terceira folha totalmente desenvolvida, a partir do ápice em $\mathrm{R}_{6}$. As folhas foram secas em estufa de circulação forçada de ar e moídas e o teor de nitrogênio foi determinado pela destilação com arrasto de vapores, utilizando-se o Método Kjeldahl); componentes da produção (coletadas 10 plantas por tratamento e efetuadas as contagens); e produtividade de grãos (foram colhidas as três linhas centrais com quatro metros de comprimento e os dados transformados em $\mathrm{kg} \mathrm{ha}^{-1}$, à base úmida de 13\%).
Os dados foram submetidos a análise de variância (Teste $\mathrm{F}$ ) e as médias comparadas pelo teste Tukey (5\%), com o auxílio do programa Sanest (Zonta \& Machado 1986).

\section{RESULTADOS E DISCUSSÃO}

O florescimento pleno ocorreu aos 41 e 43 dias após a emergência das plântulas e a cultura apresentou ciclo de 90 e 94 dias, em 2003 e 2004, respectivamente. Na Tabela 2, são apresentados os resultados referentes à massa seca de plantas, teor de nitrogênio na folha, número de vagens por planta e de grãos por planta do feijoeiro de inverno irrigado, em função das fontes e da incorporação de nitrogênio em cobertura. É importante relatar que, no segundo ano de cultivo, muitos dos fatores relacionados à produção das plantas não sofreram influência exclusiva da adubação nitrogenada, devido à ocorrência, na área de cultivo, do mosaico dourado do feijoeiro, que, mesmo com o monitoramento e controle do vetor, limitou a capacidade das plantas afetadas em assimilar o nitrogênio aplicado.

No que se refere à incorporação do nitrogênio aplicado, esta prática não influenciou qualquer parâmetro estudado, nos dois anos de cultivo (Tabela 2). Neste caso, há duas hipóteses para a ausência de resposta destes tratamentos: 1) por se tratar de uma área irrigada, o solo se apresentava úmido, no momento da aplicação do nitrogênio, mesmo nas parcelas sem incorporação, e isto pode ter causado uma movimentação do $\mathrm{N}$ em profundidade, favorecendo a utilização deste nutriente pelas plantas; 2) não descarta-se a hipótese de que, nos tratamentos com incorporação do nitrogênio pela água de irrigação, possa ter ocorrido volatilização do $\mathrm{N}$, devido ao aumento da atividade da enzima uréase, que ocorre em solos mais úmidos (Volk 1966), não evidenciando, assim, diferenças significativas na incorporação deste elemento.

A combinação de fontes de nitrogênio influenciou a massa seca de plantas apenas no ano de 2003 (Tabela 2). Resultados semelhantes foram verificados por Chidi et al. (2002) e Silva et al. (2004), os quais encontraram aumento na massa seca, com a aplicação de nitrogênio. Este aumento é resultado da maior disponibilidade de $\mathrm{N}$ para as plantas de feijão, ocorrendo, assim, incremento na absorção do mesmo. Por outro lado, Romanini Júnior et al. (2005) não verificaram efeito da adubação nitrogenada neste 
Tabela 2. Massa seca de plantas, teor de $\mathrm{N}$ foliar, número de vagens por planta e número de grãos por planta, em função da combinação de fontes de N (sulfato de amônio - SA e ureia -U), com ou sem incorporação com água de irrigação (Selvíria, MS, 2003/2004).

\begin{tabular}{|c|c|c|c|c|c|c|c|c|}
\hline \multirow{3}{*}{ Tratamentos } & \multicolumn{2}{|c|}{ Massa seca de plantas } & \multicolumn{2}{|c|}{ Teor de $\mathrm{N}$ foliar } & \multicolumn{2}{|c|}{$\mathrm{N}^{\mathrm{o}}$ de vagens planta ${ }^{-1}$} & \multicolumn{2}{|c|}{$\mathrm{N}^{\mathrm{o}}$ de grãos planta ${ }^{-1}$} \\
\hline & 2003 & 2004 & 2003 & 2004 & 2003 & 2004 & 2003 & 2004 \\
\hline & \multicolumn{2}{|c|}{ g planta $^{-1}$} & \multicolumn{2}{|c|}{$\mathrm{g} \mathrm{kg}^{-1}$} & & & & \\
\hline \multicolumn{9}{|l|}{ Combinações de fontes de $\mathrm{N}$} \\
\hline Testemunha $($ sem $\mathrm{N})$ & $6,2 \mathrm{~b}$ & 5,9 & $26,7 \mathrm{~b}$ & 39,4 & $7,5 \mathrm{~b}$ & 7,3 & $32,5 \mathrm{~b}$ & 29,1 \\
\hline $80 \mathrm{~kg} \mathrm{~N}(\mathrm{SA})$ & $10,0 \mathrm{a}$ & 8,0 & $32,5 \mathrm{a}$ & 41,2 & $9,2 \mathrm{ab}$ & 7,6 & $37,1 \mathrm{ab}$ & 39,4 \\
\hline $60 \mathrm{~kg} \mathrm{~N}(\mathrm{SA})+20 \mathrm{~kg} \mathrm{~N}(\mathrm{U})$ & $10,9 \mathrm{a}$ & 7,6 & $32,7 \mathrm{a}$ & 41,4 & $10,9 \mathrm{a}$ & 7,8 & $46,5 \mathrm{a}$ & 35,7 \\
\hline $40 \mathrm{~kg} \mathrm{~N}(\mathrm{SA})+40 \mathrm{~kg} \mathrm{~N}(\mathrm{U})$ & $10,5 \mathrm{a}$ & 8,5 & $31,2 \mathrm{a}$ & 42,4 & $9,4 a b$ & 8,5 & $39,6 \mathrm{ab}$ & 38,6 \\
\hline $20 \mathrm{~kg} \mathrm{~N}(\mathrm{SA})+60 \mathrm{~kg} \mathrm{~N}(\mathrm{U})$ & $9,1 \mathrm{ab}$ & 8,0 & $30,0 \mathrm{ab}$ & 40,6 & $9,2 \mathrm{ab}$ & 7,8 & $41,2 \mathrm{ab}$ & 41,1 \\
\hline $80 \mathrm{~kg} \mathrm{~N}(\mathrm{U})$ & $9,6 \mathrm{ab}$ & 8,1 & $30,0 \mathrm{ab}$ & 46 & $10,6 \mathrm{a}$ & 9,2 & $46,8 \mathrm{a}$ & 42,9 \\
\hline \multicolumn{9}{|l|}{ Incorporação de $\mathrm{N}$} \\
\hline Não incorporado & 9,4 & 7,6 & 29,8 & 40,5 & 9,4 & 7,9 & 40,1 & 37,2 \\
\hline Incorporado & 9,3 & 7,8 & 31,4 & 42 & 9,8 & 8,1 & 41,2 & 38,4 \\
\hline \multicolumn{9}{|l|}{ Teste F } \\
\hline Fontes de N ( F ) & $4,17 * *$ & $2,21^{\mathrm{ns}}$ & $4,54 * *$ & $0,15^{\mathrm{ns}}$ & $3,23 *$ & $2,04^{\mathrm{ns}}$ & $3,03 *$ & $1,74^{\text {ns }}$ \\
\hline Incorporação ( I ) & $0,01^{\mathrm{ns}}$ & $0,05^{\mathrm{ns}}$ & $3,63^{\mathrm{ns}}$ & $0,28^{\mathrm{ns}}$ & $0,40^{\mathrm{ns}}$ & $0,38^{\mathrm{ns}}$ & $0,19^{\text {ns }}$ & $0,12^{\mathrm{ns}}$ \\
\hline F x I & $0,28^{\mathrm{ns}}$ & $1,26^{\mathrm{ns}}$ & $2,05^{\mathrm{ns}}$ & $0,63^{\text {ns }}$ & $0,71^{\mathrm{ns}}$ & $0,31^{\mathrm{ns}}$ & $0,68^{\mathrm{ns}}$ & $1,46^{\mathrm{ns}}$ \\
\hline DMS (Fontes de N) & 3,5 & 2,9 & 4,3 & 9,3 & 2,9 & 2,4 & 13,5 & 14,4 \\
\hline DMS (Incorporação) & 2,9 & 1,7 & 2,1 & 8,3 & 1,3 & 1,1 & 5,3 & 6,2 \\
\hline C.V. $(\%)$ & 24,50 & 22,52 & 9,42 & 11,60 & 19,96 & 17,11 & 22,06 & 27,91 \\
\hline
\end{tabular}

parâmetro, quando comparado à ausência de $\mathrm{N}$, contrastando com o resultado desta pesquisa.

Quanto ao teor de nitrogênio na folha (Tabela 2), não observou-se influência das fontes de nitrogênio, nos dois anos de cultivo. Resultados semelhantes foram obtidos por Binotti et al. (2005). Entretanto, com relação à testemunha, a aplicação de nitrogênio influenciou o teor de $\mathrm{N}$ no primeiro ano, sendo significativamente superior para os tratamentos com $80 \mathrm{~kg} \mathrm{ha}^{-1}$ de N (SA), $60 \mathrm{~kg} \mathrm{ha}^{-1}$ de N (SA) + $20 \mathrm{~kg} \mathrm{ha}^{-1}$ de N (U) e $40 \mathrm{~kg} \mathrm{ha}^{-1} \mathrm{de} \mathrm{N}(\mathrm{SA})+40 \mathrm{~kg} \mathrm{ha}^{-1}$ de N(U). Tal aumento no teor de clorofila, em relação à testemunha, quando utilizou-se adubação nitrogenada, também foi verificado por Carvalho et al. (2003).

O número de vagens por planta não diferiu entre as combinações de fontes de nitrogênio utilizadas para o ano de 2004, enquanto, no ano de 2003, os tratamentos com $60 \mathrm{~kg} \mathrm{ha}^{-1}$ de N (SA) $+20 \mathrm{~kg} \mathrm{ha}^{-1}$ de $\mathrm{N}(\mathrm{U})$ e $80 \mathrm{~kg} \mathrm{ha}^{-1}$ de N (U) diferiram da testemunha, porém, não diferiram das outras combinações de fontes de nitrogênio (Tabela 2). Arf et al. (1992) e Carvalho et al. (2001) não verificaram diferenças no número de vagens por planta, com a utilização de diferentes fontes de nitrogênio (ureia e sulfato de amônio). Incrementos no número de vagens por planta, com a adubação nitrogenada, também foram observados por Alvarez et al. (2005).

As fontes de nitrogênio (isoladas ou combinadas) em cobertura não influenciaram no número de grãos por planta, nos dois anos do experimento (Tabela 2). O mesmo foi observado por Alvarez et al. (2005). Já a aplicação de nitrogênio em cobertura, independentemente da fonte utilizada, propiciou, no primeiro ano de cultivo, aumento significativo no número de grãos por planta (Tabela 2 ), em relação à testemunha, devido ao aumento no número de vagens por planta (Tabela 2). No segundo ano de cultivo, não se verificou efeito significativo da aplicação de nitrogênio em cobertura.

O número de grãos por vagem não foi influenciado por nenhum dos tratamentos (Tabela 3 ), talvez por ser esta característica intrínseca à cultivar utilizada, sendo pouco influenciada pelas práticas culturais utilizadas na cultura. Arf et al. (1992) e Alvarez et al. (2005) também não verificaram efeitos de fontes e Rapassi et al. (2003) não observaram efeitos de doses 
de $\mathrm{N}$ neste componente de produção do feijoeiro. A massa de 100 grãos também não foi afetada pelas fontes de nitrogênio em cobertura, nos dois anos de cultivo, bem como pela aplicação do nitrogênio ou sua incorporação com água de irrigação (Tabela 3 ). Diniz et al. (1996) observaram aumento na massa de 100 grãos, com a aplicação de $30 \mathrm{~kg} \mathrm{ha}^{-1}$ de N, em relação à testemunha. Já Araújo et al. (1987) verificaram resultados conflitantes, com relação a esta avaliação, em que doses de $30 \mathrm{~kg} \mathrm{ha}^{-1}$ e $90 \mathrm{~kg} \mathrm{ha}^{-1} \mathrm{de}$ N proporcionaram valores de massa de 100 grãos significativamente superiores aos obtidos com $60 \mathrm{~kg} \mathrm{ha}^{-1}$ de $\mathrm{N}$, porém, não diferiram, significativamente, da testemunha.

As fontes de nitrogênio (isoladas ou combinadas) em cobertura não interferiram na produtividade de grãos do feijoeiro, nos dois anos de cultivo (Tabela 3). Isto talvez tenha ocorrido porque as aplicações de $\mathrm{N}$ em cobertura foram realizadas em período de temperatura mais amena e, consequentemente, reduziu-se a volatilização de $\mathrm{N}-\mathrm{NH}_{3}$. Também pode ter ocorrido absorção do $\mathrm{NH}_{3}$ presente na atmosfera, abaixo do dossel das folhas inferiores das plantas. Barbosa Filho \& Silva (2001), Rapassi et al. (2003) e Alvarez et al. (2005) verificaram que a produtividade do feijoeiro não foi afetada por diferentes fontes de nitrogênio. Resultados semelhantes foram observados por Binotti et al. (2004), que, utilizando ureia, sulfato de amônio e mistura $(1 / 2$ de $\mathrm{N}$ da ureia $+1 / 2$ de $\mathrm{N}$ do sulfato de amônio), não verificaram influência na produtividade do feijoeiro de inverno.

No ano de 2003, a aplicação de nitrogênio em cobertura proporcionou aumento na produtividade do feijoeiro, na dose testada de $80 \mathrm{~kg} \mathrm{ha}^{-1}$ (Tabela 3), independentemente da fonte, já que, também, propiciou aumento na massa seca de plantas, teor de nitrogênio e número de vagens por planta, neste ano de cultivo. Isto acarretou produtividade de grãos superior, quando se forneceu nitrogênio em cobertura via adubação mineral, evidenciando que o feijoeiro de inverno irrigado em sistema de semeadura direta responde à aplicação do elemento. Meira et al. (2005) também verificaram resposta positiva do feijoeiro a adubações elevadas, com doses acima de $140 \mathrm{~kg} \mathrm{ha}^{-1} \mathrm{de} \mathrm{N}$.

Tabela 3. Número de grãos por vagem, massa de 100 grãos e produtividade de grãos do feijoeiro, em função da combinação de fontes de N (sulfato de amônio - SA e ureia - U), com ou sem incorporação com água de irrigação (Selvíria, MS, 2003/2004).

\begin{tabular}{|c|c|c|c|c|c|c|}
\hline \multirow{3}{*}{ Tratamentos } & \multicolumn{2}{|c|}{$\mathrm{N}^{\mathrm{o}}$ de grãos vagem ${ }^{-1}$} & \multicolumn{2}{|c|}{ Massa de 100 grãos } & \multicolumn{2}{|c|}{ Produtividade } \\
\hline & 2003 & 2004 & 2003 & 2004 & 2003 & 2004 \\
\hline & & & \multicolumn{2}{|c|}{$-g$} & \multicolumn{2}{|c|}{$\mathrm{kg} \mathrm{ha}^{-1}$} \\
\hline \multicolumn{7}{|l|}{ Combinações de fontes de $\mathrm{N}$} \\
\hline Testemunha & 4,4 & 4,0 & 19,6 & 24,1 & $1411 b$ & $1263 \mathrm{~b}$ \\
\hline 80 kg N (SA) & 4,0 & 5,1 & 20,8 & 24,7 & $1611 \mathrm{a}$ & $1548 \mathrm{ab}$ \\
\hline $60 \mathrm{~kg} \mathrm{~N}(\mathrm{SA})+20 \mathrm{~kg} \mathrm{~N}(\mathrm{U})$ & 4,3 & 4,5 & 20,4 & 25,1 & $1791 \mathrm{a}$ & 1586 a \\
\hline $40 \mathrm{~kg} \mathrm{~N}(\mathrm{SA})+40 \mathrm{~kg} \mathrm{~N}(\mathrm{U})$ & 4,2 & 4,5 & 19,9 & 25,0 & $1688 \mathrm{a}$ & $1580 \mathrm{a}$ \\
\hline $20 \mathrm{~kg} \mathrm{~N}(\mathrm{SA})+60 \mathrm{~kg} \mathrm{~N}(\mathrm{U})$ & 4,1 & 5,3 & 20,5 & 25,0 & $1701 \mathrm{a}$ & $1458 \mathrm{ab}$ \\
\hline 80 kg N (U) & 4,4 & 4,7 & 20,4 & 24,8 & $1754 \mathrm{a}$ & $1567 \mathrm{ab}$ \\
\hline \multicolumn{7}{|l|}{ Incorporação do N } \\
\hline Não incorporado & 4,2 & 4,7 & 20,3 & 25,0 & 1675 & 1548 \\
\hline Incorporado & 4,2 & 4,7 & 20,3 & 24,6 & 1670 & 1452 \\
\hline \multicolumn{7}{|l|}{ Valor de F } \\
\hline Fontes de N ( F ) & $1,39^{\mathrm{ns}}$ & $2,06^{\mathrm{ns}}$ & $1,92^{\text {ns }}$ & $0,81^{\mathrm{ns}}$ & $4,42 * *$ & $2,95^{*}$ \\
\hline Incorporação ( I ) & $0,18^{\mathrm{ns}}$ & $0,03^{\text {ns }}$ & $0,004^{\mathrm{ns}}$ & $1,22^{\text {ns }}$ & $0,01^{\text {ns }}$ & $2,62^{\text {ns }}$ \\
\hline $\mathrm{F} \times \mathrm{I}$ & $0,50^{\text {ns }}$ & $0,73^{\text {ns }}$ & $0,28^{\mathrm{ns}}$ & $1,55^{\mathrm{ns}}$ & $0,38^{\mathrm{ns}}$ & $1,26^{\mathrm{ns}}$ \\
\hline DMS Fontes de $\mathrm{N}$ & 0,6 & 1,5 & 1,3 & 1,5 & 273,53 & 311,33 \\
\hline DMS Incorporação & 0,4 & 0,9 & 0,6 & 0,7 & 73,2 & 89,5 \\
\hline C.V. $(\%)$ & 8,66 & 19,38 & 4,32 & 4,43 & 10,81 & 13,71 \\
\hline
\end{tabular}


No segundo ano de cultivo, verificou-se, também, aumento da produtividade de grãos, com o fornecimento de nitrogênio à dose testada de $80 \mathrm{~kg} \mathrm{ha}^{-1}$, independentemente da fonte, porém, de maneira menos expressiva que no primeiro ano, possivelmente pela ocorrência na área, neste ano, de pequeno ataque de mosaico dourado do feijoeiro. Neste mesmo ano, as combinações de $60 \mathrm{~kg} \mathrm{ha}^{-1}$ de N $(\mathrm{SA})+20 \mathrm{~kg} \mathrm{ha}^{-1} \mathrm{de} \mathrm{N}(\mathrm{U})$ e $40 \mathrm{~kg} \mathrm{ha}^{-1}$ de N (SA) + $40 \mathrm{~kg} \mathrm{ha}^{-1}$ de $\mathrm{N}(\mathrm{U})$ proporcionaram incrementos significativos, em relação à testemunha, com ganhos de $323 \mathrm{~kg} \mathrm{ha}^{-1}$ e $317 \mathrm{~kg} \mathrm{ha}^{-1}$, respectivamente, enquanto os demais tratamentos não diferiram da testemunha. Embora não tenham sido evidenciadas diferenças significativas entre as combinações de fontes de nitrogênio, ressalta-se que o uso de ureia como fertilizante nitrogenado pode ser mais vantajoso, por apresentar menor custo, em relação ao sulfato de amônio, podendo, assim, garantir maior lucratividade ao produtor.

É importante salientar que a produtividade média do feijoeiro não foi a esperada, principalmente no segundo ano de cultivo, em decorrência, dentre outros fatores, de a cultura antecessora ter sido o milho. Silveira et al. (2001) analisaram o comportamento do feijoeiro cultivado em diferentes rotações de culturas e observaram menores produtividades nas rotações cuja cultura antecedente era o milho.

Nota-se que os resultados encontrados na literatura, a respeito da adubação nitrogenada, são controversos. Ambrosano et al. (1996) verificaram respostas diferentes para a aplicação de $\mathrm{N}$, de um ano para outro, no município de Votuporanga (SP). Estas divergências na resposta do feijoeiro à adubação nitrogenada podem estar relacionadas ao ciclo curto do feijoeiro (90 a 100 dias) e ao seu sistema radicular pouco desenvolvido, estando sujeito a queda na produtividade, em função de qualquer tipo e nível de estresse (Almeida et al. 2000). Além disto, cultivares diferentes e condições de clima e de solo determinam a resposta da cultura à aplicação do nutriente, e, ainda, conforme ressaltado por Rosolem (1996), as condições de respostas à aplicação de nitrogênio estão sujeitas à situação do solo e do local de semeadura (cultura anterior, teor de matéria orgânica, compactação do solo, textura do solo e irrigação), de forma que o histórico da área de implantação da cultura é fundamental na previsão da dose e potencial de resposta ao referido nutriente.

\section{CONCLUSÕES}

1. O fornecimento de nitrogênio às plantas, na dose de $80 \mathrm{~kg} \mathrm{ha}^{-1}$, independentemente da combinação de fontes (isoladas ou em mistura), propicia aumento na produtividade de grãos.

2. A incorporação ou não do fertilizante nitrogenado ao solo com água de irrigação não interfere nos componentes de produção e produtividade do feijoeiro de inverno.

\section{REFERÊNCIAS}

ALMEIDA, C. et al. Ureia em cobertura e via foliar em feijoeiro. Scientia Agricola, Piracicaba, v. 57, n. 2, p. 293298, 2000.

ALVAREZ, A. C. C. et al. Resposta do feijoeiro à aplicação de doses e fontes de nitrogênio em cobertura no sistema de plantio direto. Acta Scientiarum, Maringá, v. 27, n. 1, p. 69-75, 2005.

AMBROSANO, E. J. et al. Efeito do nitrogênio no cultivo de feijão irrigado no inverno. Scientia Agricola, Piracicaba, v. 53, n. 2-3, p. 338-342, 1996.

ARAÚJO, G. A. A. et al. Influência do molibdênio e do nitrogênio sobre duas variedades de feijão (Phaseolus vulgaris L.). Revista Ceres, Viçosa, v. 34, n. 2, p. 333339, 1987.

ARF, O. et al. Comparação de fontes e doses de adubos nitrogenados na cultura do feijoeiro (Phaseolus vulgaris, L.), cultivo no sistema de "plantio direto". Cultura Agronomica, Ilha Solteira, v. 1, n. 1, p. 21-30, 1992.

ARF, O. et al. Efeitos de doses e parcelamento da adubação nitrogenada em cobertura na cultura do feijão (Phaseolus vulgaris L.). In: REUNIÃO NACIONAL DE PESQUISA DE FEIJÃO, 6., 1999, Salvador. Resumos expandidos... Santo Antônio de Goiás: Embrapa, 1999. p. 790-793.

BARBOSA FILHO, M. P.; SILVA, O. F. Adubação de cobertura do feijoeiro irrigado com ureia fertilizante em plantio direto: um ótimo negócio. Informações Agronômicas, Piracicaba, n. 93, p. 1-5, 2001.

BARBOSA FILHO, M. P.; FAGERIA, N. K.; SILVA, O. F. Fontes e métodos de aplicação de nitrogênio em feijoeiro irrigado submetido a três níveis de acidez do solo. Ciência e Agrotecnologia, Lavras, v. 28, n. 4, p. 785-792, 2004.

BINOTTI, F. F. S. et al. Doses e fontes de nitrogênio em cobertura em feijoeiro de inverno irrigado no sistema plantio direto. In: CONGRESSO NACIONAL DE PESQUISA DE FEIJÃO, 8., 2005, Goiânia. Anais... Goiânia: Embrapa, 2005. p. 979-982. 
BINOTTI, F. F. S. et al. Época de aplicação e fontes de nitrogênio em cobertura, na cultura do feijão em sistema plantio direto. In: REUNIÃO BRASILEIRA DE FERTILIDADE DE SOLOS E NUTRIÇÃO DE PLANTAS, 26., 2004, Lages. Anais... Lages: SBCS/Udesc, 2004. 1 CD-ROM.

CARVALHO, M. A. C. et al. Doses e épocas de aplicação de nitrogênio e teores foliares deste nutriente e de clorofila em feijoeiro. Revista Brasileira de Ciência do Solo, Viçosa, v. 27, n. 3, p. 445-450, 2003.

CARVALHO, M. A. C. et al. Produtividade e qualidade de sementes de feijoeiro (Phaseolus vulgaris L.) sob influência de parcelamentos e fontes de nitrogênio. Revista Brasileira de Ciência do Solo,Viçosa, v. 25, n. 3, p. 617 624, 2001.

CHIDI, S. N. et al. Nitrogênio via foliar e em cobertura em feijoeiro irrigado. Acta Scientiarum, Maringá, v. 24, n. 5, p. 1391-1395, 2002.

DINIZ, A. R. et al. Resposta da cultura do feijoeiro (Phaseolus vulgaris L.) à aplicação de nitrogênio (cobertura e semeadura) e de molibdênio foliar. In: REUNIÃO NACIONAL DE PESQUISA DE FEIJÃO, 5., 1996, Goiânia. Anais... Goiânia: Embrapa, 1996. p. 73-75.

EMPRESA BRASILEIRA DE PESQUISA AGROPECUÁRIA (Embrapa). Centro Nacional de Pesquisa de Solos. Sistema brasileiro de classificação de solos. 2. ed. Rio de Janeiro: Embrapa, 2006.

LARA CABEZAS, W. A. R. et al. Balanço da adubação nitrogenada sólida e fluida de cobertura na cultura do milho, em sistema plantio direto no Triângulo Mineiro (MG). Revista Brasileira de Ciência do Solo, Viçosa, v. 24, n. 3, p. 363-376, 2000.

MEIRA, F. A. et al. Doses e épocas de aplicação de nitrogênio no feijoeiro irrigado cultivado em plantio direto. Pesquisa Agropecuária Brasileira, Brasília, DF, v. 40, n. 4, p. 383-388, 2005.

RAIJ, B.; QUAGGIO, J. A. Métodos de análises de solo para fins de fertilidade. Campinas: Instituto Agronômico, 1983.

RAPASSI, R. M. A. et al. Níveis e fontes de nitrogênio sobre o feijoeiro de inverno. Cultura Agronômica, Ilha Solteira, v. 12, n. 1, p. 103-115, 2003.
ROMANINI JÚNIOR, A. et al. Mecanismo de abertura de sulco para deposição do fertilizante e aplicação de nitrogênio em cobertura em feijão de inverno sob plantio direto. In: CONGRESSO NACIONAL DE PESQUISA DE FEIJÃO, 8., 2005, Goiânia. Anais... Goiânia: Embrapa, 2005. p. 831-833.

ROSA, G. J. B. et al. Volatilização de amônia de diferentes formulados na adubação nitrogenada e seu efeito no crescimento do cafeeiro. In: REUNIÃO BRASILEIRA DE FERTILIDADE DE SOLOS E NUTRIÇÃO DE PLANTAS, 26., 2004, Lages. Anais... Lages: SBCS/ Udesc, 2004. p. 1-4.

ROSOLEM, C. A. Calagem e adubação mineral. In: ARAÚJO, R. S. et al. (Coords.). Cultura do feijoeiro comum no Brasil. Piracicaba: Potafos, 1996. p. 353-390.

SILVA, M. G. et al. Manejo do solo e adubação nitrogenada em feijoeiro de inverno. Scientia Agricola, Piracicaba, v. 61, n. 3, p. 307-312, 2004.

SILVEIRA, P. M. et al. Efeitos do preparo do solo, plantio direto e de rotações de culturas sobre o rendimento e a economicidade do feijoeiro irrigado. Pesquisa Agropecuária Brasileira, Brasília, DF, v. 36, n. 2, p. 257 263, 2001.

VILLAS BOAS, R. L. et al. Recuperação do nitrogênio da mistura de ureia e sulfato de amônio por plantas do milho. Bragantia, Campinas, v. 64, n. 2, p. 263-272, 2005.

VITTI, G. C. et al. Influência da mistura de sulfato de amônio com ureia sobre a volatilização de nitrogênio amoniacal. Revista Brasileira de Ciência do Solo, Viçosa, v. 26, n. 3, p. 663-671, 2002.

VOLK, G. M. Efficiency of urea as affected by method of application, soil moisture and lime. Agronomy Journal, Madison, n. 58, p. 248-252, 1966.

VOLK, G. M. Volatile loss of ammonia following surface application of urea to turf of bare soils. Agronomy Journal, Madison, n. 51, p. 746-749, 1959.

ZONTA, E. P.; MACHADO, A. A. Sistema de análise estatística para microcomputadores: Sanest. Pelotas: UFPel, 1986. 